Methods Questionnaires were distributed via SurveyMonkey to the 59 trainees being assessed and the 37 assessors, with a respective response rate of $74.6 \%$ and $73 \%$. A semi-structured approach collected data using Likert scales, combined with open ended questions.

Analysis addressed both quality and organisational issues. Summarised responses to the Likert scales are reported. Open ended questions were explored using thematic content analysis and main areas for development visualised with word clouds. Follow up data will be analysed and reported using a longitudinal approach to examine the impact of reflective changes to practise following the feedback from the assessment.

Results $74.4 \%$ of trainees and $100 \%$ of assessors recognised START as a good assessment of skills that are not assessed elsewhere such as safe prescribing, critical appraisal and management of complexity. $64.3 \%$ of trainees and $100 \%$ of assessors noted that START was a good assessment of 'readiness' for consultant practise. START assesses a range of skills requiring appropriate leadership and understanding team dynamics.

Assessors identified leadership, prioritisation, multidisciplinary working and decision making as being the most predominant areas for development when considering all the trainees. This differed slightly from areas identified for development within the subspecialties which included knowledge.

Assessors believe START will impact on trainees' learning and practise behaviour, emphasising importance of reflection and identified action on the feedback. They consider it fit for purpose in helping with the transition of becoming a consultant and focussing the trainees on areas needed for further development. This information prompts trainees to actively seek opportunities in identified domains to improve and gain further experience. Future longitudinal follow-up evaluation and analysis of the impact of START will be undertaken.

Conclusion START provides new and useful feedback on trainee's behaviour and practise and a focused learning plan in readiness for consultant practise. Initial findings indicate the importance of attitude and 'buy in' amongst trainees.

\section{G08 PERFORMANCE DEBRIEFING IN PAEDIATRICS: DEVELOPMENT AND PSYCHOMETRIC VALIDATION OF A NOVEL EVIDENCE-BASED DEBRIEFING INSTRUMENT}

\author{
doi:10.1136/archdischild-2013-304107.021
}

1J Runnacles, ${ }^{2} \mathrm{~L}$ Thomas, ${ }^{3} \mathrm{~N}$ Sevdalis, ${ }^{4} \mathrm{M}$ Cooper, ${ }^{3} \mathrm{~S}$ Arora. ${ }^{1}$ Department of Paediatrics, Kingston Hospital NHS Trust, Kingston- upon- Thames, UK; '2 Simulation and interactive learning centre (SalL), Guy's and St Thomas' Hospital, London, UK; ' ${ }^{3}$ Department of Surgery and Cancer, Imperial College London, London, UK; ${ }^{4}$ Department of Paediatrics, Imperial College Healthcare NHS Trust, London, UK

Aims Simulation offers paediatric trainees the opportunity of practised experience in a safe learning environment. Performance debriefing (facilitated or guided reflection in the cycle of experiential learning) is essential to maximise the learning experience, but there is currently little evidence-based guidance on effective paediatric debriefings. This study aimed to develop a debriefing assessment tool in order to assess the quality of feedback in paediatric simulation debriefings, and to evaluate its validity, inter-rater reliability, and feasibility.

Methods A literature review (phase 1) and semi-structured interviews with 16 paediatricians (phase 2) were used to identify key elements of a paediatric debriefing. Emergent theme analysis of these key elements was used to identify dimensions for inclusion in a novel "Objective Structured Assessment of Debriefing" for Paediatrics tool (OSAD). Expert input on the tool was sought from ten experienced paediatric simulation debriefing facilitators to provide further input to OSAD (content validation; feasibility). Evidence for inter-rater reliability was sought from video ratings of 35 debriefings after simulation scenarios of a seriously ill child. Concurrent validity was assessed via correlations of OSAD scores with trainees' self-ratings of the quality of debriefings they received.

Results The literature review identified 34 relevant studies on debriefing. 307 key elements were identified from the literature review and 16 interviews. Key elements were thematically grouped into eight dimensions representing the desired features of a paediatric debriefing, which make up OSAD (Figure 1). The simulation

\begin{tabular}{|c|c|c|c|}
\hline & 1 & 3 & 5 \\
\hline 1. Approach & Confrontational, judgmental approach & $\begin{array}{c}\text { Attempts to establish rapport with the learner(s) } \\
\text { but is either over- critical or too informal in } \\
\text { manner }\end{array}$ & $\begin{array}{c}\text { Establishes and maintains rapport throughout; uses a } \\
\text { non- threatening but honest approach to create a } \\
\text { psychologically safe environment }\end{array}$ \\
\hline $\begin{array}{l}\text { 2. Establishes learning } \\
\text { environment }\end{array}$ & $\begin{array}{c}\text { Unclear expectations of the learner(s); inadequate } \\
\text { learning environment }\end{array}$ & $\begin{array}{c}\text { Explains purpose of the debriefing or learning } \\
\text { session but does not clarify learner(s) } \\
\text { expectations }\end{array}$ & $\begin{array}{l}\text { Explains purpose of debrief; clarifies objectives and } \\
\text { learner expectations from the beginning }\end{array}$ \\
\hline 3. Engagement of Learners & $\begin{array}{c}\text { Purely didactic; facilitator doing all of the talking } \\
\text { with no learner engagement; does not involve } \\
\text { passive learner(s) }\end{array}$ & $\begin{array}{c}\text { Learner(s) participates in the discussion but } \\
\text { through closed questions; facilitator does not } \\
\text { actively invite input from more passive learner(s) }\end{array}$ & $\begin{array}{c}\text { Encourages participation of learner(s) through } \\
\text { open-ended questions; invites learner(s) to actively } \\
\text { contribute to discussion }\end{array}$ \\
\hline 4. Reaction & $\begin{array}{l}\text { No acknowledgment of learner(s)' reactions, or } \\
\text { emotional impact of the experience }\end{array}$ & $\begin{array}{l}\text { Asks the learner(s) about their feelings but does } \\
\text { not fully explore their reaction to the experience }\end{array}$ & $\begin{array}{c}\text { Fully explores learner(s)'s reaction to the experience, } \\
\text { appropriately managing any learner(s) who is } \\
\text { confused or unhappy }\end{array}$ \\
\hline 5. Descriptive Reflection & $\begin{array}{l}\text { No opportunity for self- reflection; learner(s) not } \\
\text { asked to describe what actually happened in the } \\
\text { scenario }\end{array}$ & $\begin{array}{c}\text { Some description of events by facilitator, but with } \\
\text { little self-reflection by learner(s) }\end{array}$ & $\begin{array}{c}\text { Encourages learner(s) to self-reflect upon experience } \\
\text { using a step by step approach }\end{array}$ \\
\hline 6. Analysis & $\begin{array}{l}\text { Reasons and consequences of actions are not } \\
\text { explored with the learner(s) }\end{array}$ & $\begin{array}{c}\text { Some exploration of reasons and consequences of } \\
\text { actions by facilitator but not learner(s) }\end{array}$ & $\begin{array}{l}\text { Helps learner(s) to explore reasons and conse- } \\
\text { quences of actions, identifying specific examples; } \\
\text { relates it back to previous experience to offer } \\
\text { explanations }\end{array}$ \\
\hline 7. Diagnosis & $\begin{array}{c}\text { No feedback on clinical or teamwork skills; does } \\
\text { not identify performance gaps or provide positive } \\
\text { reinforcement }\end{array}$ & $\begin{array}{l}\text { Feedback provided only on clinical (technical) } \\
\text { skills; focuses on errors only; does not target } \\
\text { behaviours that can be changed. }\end{array}$ & $\begin{array}{c}\text { Provides feedback on clinical (technical) and } \\
\text { teamwork skills; identifies positive behaviours in } \\
\text { addition to performance gaps, targets changeable } \\
\text { behaviours }\end{array}$ \\
\hline 8. Application & $\begin{array}{l}\text { No opportunity for learner(s) to identify } \\
\text { strategies for future improvement or to } \\
\text { consolidate key learning points }\end{array}$ & $\begin{array}{c}\text { Some discussion of learning points and strategies } \\
\text { for improvement but lack of application of this } \\
\text { knowledge to future practice }\end{array}$ & $\begin{array}{c}\text { Reinforces key learning points identified by learner(s) } \\
\text { and highlights how strategies for improvement could } \\
\text { be applied to future clinical practice }\end{array}$ \\
\hline
\end{tabular}

Abstract G08 Figure 1 Objective Structured Assessment of Debriefing (OSAD) in Paediatrics 
experts significantly agreed with the elements of debriefing included in OSAD (content validity) and found its instructions clear and intuitive (feasibility). Inter-rater reliability was demonstrated with intra-class correlations of $0.60-0.70$ for 6 of the 8 dimensions of the tool. The internal consistency of OSAD (Cronbach alpha) was 0.79 . OSAD also demonstrated concurrent validity in the form of high correlations with trainees' assessment of debriefings (Pearson $\mathrm{r}=0.71, \mathrm{p}<0.01)$

Conclusion The OSAD tool provides a structured approach to debriefing for paediatricians, which is evidence-based, reliable and valid and relevant to users. OSAD can be used to improve the quality of debriefing after paediatric simulation or after managing a seriously ill child in clinical practise.

\section{G09 DO PARENTS AGREE WITH EXAMINERS WHEN RATING STUDENT COMPETENCE IN EXAMS?}

doi:10.1136/archdischild-2013-304107.022

S Feyereislova, D Nathan. Paediatrics, Nottingham Children's Hospital, Nottingham, UK

\begin{abstract}
Aims To compare examiner and parental ratings of students undertaking a summative clinical assessment of history-taking and examination skills in a ward based setting.
\end{abstract}

Methods Parents of patients participating in the 4th year medical students' ward based assessments were asked for feedback and an evaluation of student performance through validated questionnaire. Students completed a paediatric history and head to toe examination of a child admitted to an acute medical ward within a defined time. The clinical case was presented to examiners (experienced clinicians - paediatric consultants and/or senior Trainees). Examiners ratings were based on student competence in presentation of medical history and examination findings, with observed examination technique and their communication skills during a predetermined clinical role play situation. The latter grading mirrored an $\mathrm{RCPCH}$ scoring system.

Parental ratings were based on the Interpersonal Skills Rating Scale which encompassed their impression of the student's interaction with them and their child. The data was collected in the 2011-2012 academic year. We then correlated aggregated parental scores with examiner rating of the same student.

Results In total, 129 parent evaluations were obtained for 129 students. One hundred and nine parental feedback forms were fully completed and correlated with examiners' scores of matching students. The correlation coefficient for the total scores given by parents and examiners was -0.04 , with intercept at score 22 and the slope of -0.02 . The average score given by parents is 22 (range 16-24). The average score given by examiners is 18 (range 7-24).

Conclusion In general, parental rating does not correlate with clinical examiner rating. Parental ratings of students demonstrate less variation compared to examiner rating scores. Notably, low scoring students were not necessarily considered by parents as underperforming, suggesting students' good communication and interpersonal skills irrespective of technical knowledge.

\section{G10 INSPIRING THE FUTURE OF PAEDIATRICS: A REPORT ON THE PROVISION OF PAEDIATRIC LEARNING EXPERIENCES FOR UK MEDICAL STUDENTS}

doi:10.1136/archdischild-2013-304107.023

S Fosker, R Ives, H Millar, BN Ertansel. Faculty of Medicine, Brighton \& Sussex Medical School, Brighton, UK

Aims To create an event to enhance paediatric knowledge and enthusiasm in the medical student population and establish a forum for students and internationally renowned speakers to share ideas and experiences.

Methods A two day conference was organised by a student paediatric society to welcome over 200 students from all UK medical schools and the local widening access scheme. The conference programme included workshops and lectures by Paediatricians from around the UK. Topics included general paediatric medicine and surgery, in addition to the subspecialties; neonatology, child protection, emergency medicine and child development. Overall, the event provided an opportunity for delegates to experience additional practical and theoretical tuition in paediatrics which is not widely available within most medical schools's curriculum. Additional opportunities were available to present research to visiting lecturers and host academic faculty.

Results 215 delegates attended the conference, $60 \%$ returned feedback forms. Delegates were asked to rank out of five (one being the lowest and five the highest) their experiences of: lectures, workshops, overall conference organisation, relevance and enjoyment. 40 poster titles $(18.6 \%)$ were submitted and presented during the event. Written feedback commended the patient involvement in sessions and the subspecialist topics covered.

\begin{tabular}{ll} 
Abstract G10 Table 1 \\
\hline Feedback categories & Mean Score (1-5) \\
\hline Lectures & 4.45 \\
Workshops & 4.32 \\
Overall relevance & 4.51 \\
Overall enjoyment & 4.63 \\
\hline
\end{tabular}

Conclusion The content of the lectures and workshops were well received and the overall enjoyment of the event was ranked highly. Sessions in subspecialist topics and those which included patients were particularly acclaimed. This could be secondary to limited exposure to such opportunities at medical school, which suggests that in the future the event programme should further focus on incorporating these sessions. Additionally, it was identified that students endeavour to be involved in academic paediatric research early in their educational career. Analysing the feedback provided evidence that students desire more exposure to paediatrics within their medical training. This emphasises the need for such an event to continue on an annual basis in order to further raise the profile of paediatrics and provide learning opportunities in addition to medical school curriculum.

\section{G11 PROCEDURAL OPPORTUNITIES FOR PAEDIATRIC TRAINEES}

doi:10.1136/archdischild-2013-304107.024

'K Wallace, ${ }^{2} \mathrm{D}$ Cochran. 'Neonatal Department, Wishaw General Hospital, Wishaw, UK, ${ }^{2}$ Neonatal Department, Southern General Hospital, Glasgow, UK

Aim Trainees in paediatrics are required to become competent at a number of practical procedures but often express concern at lack of opportunities. We aimed to survey the number of practical procedures undertaken in 3 months, in two level 3 neonatal units in Scotland, and how these opportunities are distributed amongst trainees.

Method Opportunities occurring for 7 procedures were documented during a 3 month period in 2 separate units, an antenatal referral centre for cardiac and surgical anomalies and a large district general hospital. Procedures recorded were intubation, umbilical arterial and venous lines (UAC, UVC), peripheral arterial lines, long lines, chest drains and lumbar punctures. Data was collected on the number of opportunities, training status of practitioner and clinical characteristics of the baby. 